Article

\title{
Gamification Risks to Enterprise Teamwork: Taxonomy, Management Strategies and Modalities of Application
}

\author{
Abdullah Algashami ${ }^{1,2, *}$, Laura Vuillier ${ }^{1}$, Amen Alrobai ${ }^{3}$, Keith Phalp ${ }^{1}$ and Raian Ali ${ }^{1}$ \\ 1 Faculty of Science and Technology, Bournemouth University, Fern Barrow, Poole BH12 5BB, UK; \\ lrenshawvuillier@bournemouth.ac.uk (L.V.); kphalp@bournemouth.ac.uk (K.P.); \\ rali@bournemouth.ac.uk (R.A.) \\ 2 Department of Computer Science and Information, College of Science, Al Zulfi 11932, P.O 1221, \\ Majmaah University, Kingdom of Saudi Arabia \\ 3 Department of Information Science, King Abdulaziz University, 21589 Jeddah, Kingdom of Saudi Arabia; \\ aaaalrobai@kau.edu.sa \\ * Correspondence: aalgashami@bournemouth.ac.uk; Tel.: +44-0120-2966-682
}

Received: 1 January 2019; Accepted: 10 February 2019; Published: 13 February 2019

check for updates

\begin{abstract}
Gamification corresponds to the use of game elements to encourage certain attitudes and behaviours in a serious context. When applied to enterprise teamwork, gamification can lead to negative side-effects which compromise its benefits. For example, applying competitive elements such as leaderboard may lead to clustering amongst team members and encourage adverse work ethics such as intimidation and pressure. Despite the recognition of the problem in the literature, the research on concretising such gamification risks is scarce. There is also a lack of methods to identify gamification risks and their management strategies. In this paper, we conduct a multi-stage qualitative research and develop taxonomy of risks, risk factors and risk management strategies. We also identify the modalities of application of these strategies, including who should be involved and how. Finally, we provide a checklist to help the risk identification process as a first step towards a comprehensive method for eliciting and managing gamification risks to teamwork within enterprises.
\end{abstract}

Keywords: gamification; risk Management; management strategy; enterprise teamwork

\section{Introduction}

Gamification is used in workplaces to increase staff desire toward implementing tasks and achieving certain goals. The set of rewarding and gaming mechanics used in gamification includes leaderboards, badges, points, as well as avatars reflecting individual and collective performance, levels and status. In the literature, various gamification techniques have been studied in various areas including health related research for encouraging a healthier lifestyle [1], business for productivity and sales solutions [2], academia to increase students' engagement in classroom activities [3], and sport to persuade users to optimise their physical activities [4]. An example of gamification technique in a call centre may involve rewarding staff for their performance in answering and solving customers' issues based on their quantity per day and clients' feedback.

Despite the benefits of gamification, its application in an enterprise has potential risks. For example, the way of calculating, assigning, and displaying rewards may increase the chance for adverse work ethics including free-riding, work intimidation, and lack of group cohesion $[5,6]$. Reviewing the literature has revealed that while gamification risks is a recognised issue, no reference models and systematic methods, to the best of our knowledge, have been developed to evaluate and mitigate these risks [7]. These risks have a peculiar nature due to their intermingled relation with 
human factors such as motivation, personality, enterprise culture and group dynamics as well as business requirements, such as increasing efficiency and quality.

In this paper, we build on our findings published in Ref. [8] which focused on conceptualising the main risks and risk factors of gamification systems to the teamwork within an enterprise. We also build on our findings presented in Ref. [9] regarding a set of management strategies to managing gamification risks and develop the main contribution of this research, which revolves around two key aspects. The first one relates to the various modalities of applications of such management strategies. This includes the different purposes of usage, styles of applications, timings and stakeholders. The second one relates to our proposal of a checklist tool, which is meant to help stakeholders in the decision-making session to identify and resolve gamification risks. In doing so, we take a significant step towards a systematic method for the elicitation, assessment, and mitigation of gamification risks to teamwork within enterprises.

\section{Literature Review}

Several studies in the literature proposed methods and principles to develop gamification. Nicholson [10] developed a user-centered theoretical framework to develop and design gamification. The framework main idea is to focus on users' needs and goals over the ones from the organisation's. Huotari and Hammari [11] argued that gamification techniques should be designed to add value to an enterprise such as increasing staff willingness to work and to increase customers satisfactions regarding the overall value of the provided services. In other words, gamification shall be engineered on top of the existing information systems. In addition, Deterding [12] emphasised the need for "meaningful play" in gamification design in which users' needs and requirements are the main focus for successful implementation of gamification, rather than the abstract rewards such as points and levels. Marczewski [13] distinguished between gamification design and features on one hand, and game design on the other hand. In this paper, he suggested that the primary design feature in games should be the enjoyment of users, while gamification design should be towards achieving business objectives.

Gamification risks have a unique nature in comparison to risks typically studied in information systems literature such as compliance and security risks. Ethical concerns and negative connotations of gamification as being an exploitation tool are increasingly becoming a primary concern when deciding to adopt gamification solutions in enterprises. In Ref. [14], Kumar and Herger identified five steps towards the design of such motivational systems and their game elements and named the approach as "Player Centred Design". The emphasis is on the awareness of ethical considerations in the design process. In Ref. [15], Apter and Kerr highlighted the unwanted effects-such as stress and anxiety-resulting from pressures for efficiency through the application of gamification on staff daily tasks. Thiebes et al. [16] conducted a systematic literature review on the design for motivation through gamification and found that research on the risks of these elements is still in its infancy and opens the way for more research in the area. Some efforts have been made to the development of ontologies that provide a formal systematisation of the knowledge on gamification and its proper application on different domains $[17,18]$. These efforts can have substantial influence on how one can understand issues of gamification, including ethical concerns and risks. In Ref. [8], we proposed a conceptualisation of the main risks factors that might occur when adding gamification to teamwork in an enterprise. Five main risks factors were identified. This includes factors in relation to staff performance in the system, goals related factors, tasks related factors, societal and personal factors and gamification elements related risks factors.

Risks of gamification systems applied in an enterprise emerge mainly from their usage or perceived usage as an appraisal and performance monitoring mechanism, as well as a pressure tool to perform better. Gamification elements can be used to motivate individuals via self-monitoring and self-comparison. For example, a progress bar can be used to encourage delivery staff to distribute a parcel within a specific time frame and following a specific process by showing them their current 
status and the remaining time and stages. Peer-comparison is another modality which can increase the perception of gamification as a pressure or intimidation tool. This includes elements such as leaderboards, levels and badges assigned to individuals but visible to all team members and meant to motivate by reflecting individual metrics, such as customers' feedback on them.

Risk management is a subject of research in various domains, including information systems, business process management, and enterprise modelling [19-25]. Risks modelling has been studied in various settings, such as in small and medium enterprises where risks should be captured and represented alongside the various stages of the system analysis and design lifecycle [26,27]. Risk management has also been studied within the area of business process management for their effect on the flow of operation and its decisions [22]. It has also been argued that the concern for compliance risks and operational risks should be incorporated during the design-time and also run-time stages of business processes [28]. Risks considered in enterprise modelling literature are mainly related to mainstream requirements such as security, privacy, compliance and capability [28,29]. Gamification engineering methods, reviewed in Ref. [30], are mainly focused on providing steps and techniques for designing the game mechanics in the first place and tend to overlook their risks. In Ref. [9], we proposed strategies that management can apply to mitigate gamification risks. The management strategies were explored from psychological and management perspectives to support a healthier and coherent implementation of such systems on business team workplaces. This led to the identification of 22 risk management strategies to minimise gamification negative consequences on team workplaces.

\section{Methodology}

We conducted a three-stage empirical study employing multiple data collection methods from various resources aiming to maximise the diversity and credibility of the results. We adopted a multistage qualitative approach [31]. Our approach stages are described in Tables 1-3.

Table 1. First stage description.

\begin{tabular}{cc}
\hline 1st Stage & Description \\
\hline Secondary analysis & Secondary analysis of data gathered in previous work conducted in Refs. $[5,7]$ \\
\hline Literature Review & Review of the related literature \\
\hline Expert Interviews & Ten interviews with experts in various related field \\
\hline
\end{tabular}

Table 2. Second stage description.

\begin{tabular}{cc}
\hline 2nd Stage & Description \\
\hline Observation study & Two months observation study in two large companies \\
\hline Interviews & Fifteen interviews with participants from related business workplaces \\
\hline
\end{tabular}

Table 3. Third stage description.

\begin{tabular}{cc}
\hline 3rd Stage & Description \\
\hline Focus group & $\begin{array}{c}\text { Seven participants with multi-disciplinary including requirements } \\
\text { engineering, human computer interaction, user modelling, cyber } \\
\text { psychology and business management }\end{array}$ \\
\hline Focus group & $\begin{array}{c}\text { Nine participants from business companies, four call center agents, one } \\
\text { project leaders, one business consultants, two IT designers and one } \\
\text { system analysts }\end{array}$ \\
\hline Interviews & Ten interviews with participants from related business workplaces \\
\hline
\end{tabular}

The first stage, shown in Table 1, was implemented to identify a preliminary set of risks of digital motivation systems and its different applications, including gamification [32], game with purpose [33] 
and persuasive technology [34]. The related literature was mainly the source of this exploration stage (i.e., first stage) including risk assessment and management [35], value sensitive design [36], and group dynamic [37]. The exploration stage resulted in an initial template of risks and their related factors. The template was the main guide for the secondary analysis of the data collected via interviews with experts, managers and end-users in gamification-related business workplaces. The results of the primary analysis are published in [38]. The primary analysis was meant for eliciting engineering practices towards accountable design and a code of ethics of gamification. This resulted in a taxonomy of risks around gamification elements and also an initial set of management strategies to address them. Both results were used as a reference for conducting ten further interviews with specialists in software engineering, psychology, as well as practitioners and managers from related business workplaces.

The second stage, presented in Table 2, was to confirm the results identified in the first stage as well as to explore further gamification risks and the main factors and situations contributing to their emergence. To achieve that, a two-months observational study was conducted in two gamified call centers in two large multicultural businesses. The purpose of the observational studies in these two companies was to increase the chance of identifying different applications of gamification elements which will help to increase the reliability and credibility of the result. Both companies have more than 50 staff including agents, supervisors, managers and IT services. Although the staff were divided into teams to answer and solve customers' calls and motivated by collective performance, there were also individual tasks within the team. A member of our research team (AA) interviewed experienced supervisors in each centre to learn about the environment, the workflow, the gamification techniques used, real statistics, and qualitative analysis of achieved results. Gamification mechanics used in the first call centre included leaderboards for teams' collective performance and badges sent by the supervisors based on individual performance. The second call centre used a point-based system in which each team worked collectively to solve customers' issues and gain points which can lead to a $10 \%$ increase in salaries at the end of the month for the winning team. Also, the names and photos of staff in the winning team were displayed on an honour board visible to all. In both companies, the role played by the researcher was a participant as observer [31] to observe the actual work environment, collect data, and have discussions with both call agents and supervisors during the observation period. In addition, this stage involved conducting interviews with fifteen people from these two workplaces to clarify the result of the observation study and also to discuss further research questions in relation to the proposed results. The interviews followed a semi-structured style. The sample of the participants included ten agents, three supervisors and two managers. The analysis of the results in the first and the second stages was the main sources for our work published in Refs. $[8,9]$.

The third stage presented in Table 3 was designed for two main purposes: (i) Managing the risks with the set of management strategies identified in previous stages and (ii) configuring the best application of these strategies to manage gamification risks. To achieve that, two focus groups were conducted, each to satisfy purpose (i) and (ii) respectively. The first focus group involved seven participants from diverse backgrounds shown in Table 3. At the start of the focus group, participants were given a presentation to familiarise them with the context of the study problem. Also, they were given scenarios to immerse them in the problem and its context. They were asked to map the strategies with the risks using two sets of cards. The second focus group involved nine participants with various years of experience in gamification in which some of them are researchers while others are belonging to business workplaces. In each scenario, a specific gamification risk was discussed followed by some questions on how to manage the risks. Finally, we conducted ten interviews with call center agents, managers, experts in related fields in order to refine the final set of results. All of the interviews followed semi-structured style.

Qualitative data collected in the studies were content analysed according to the six phases of thematic analysis proposed in Ref. [39]. All studies were reviewed and approved by the Bournemouth University Research Ethics Committee. All of the performed studies were recorded and transcribed. 
Also, all of the participants were informed about the research purpose and aims in advance and asked for their consents to participate.

\section{Results}

The result consists of four main sections described in Figure 1.

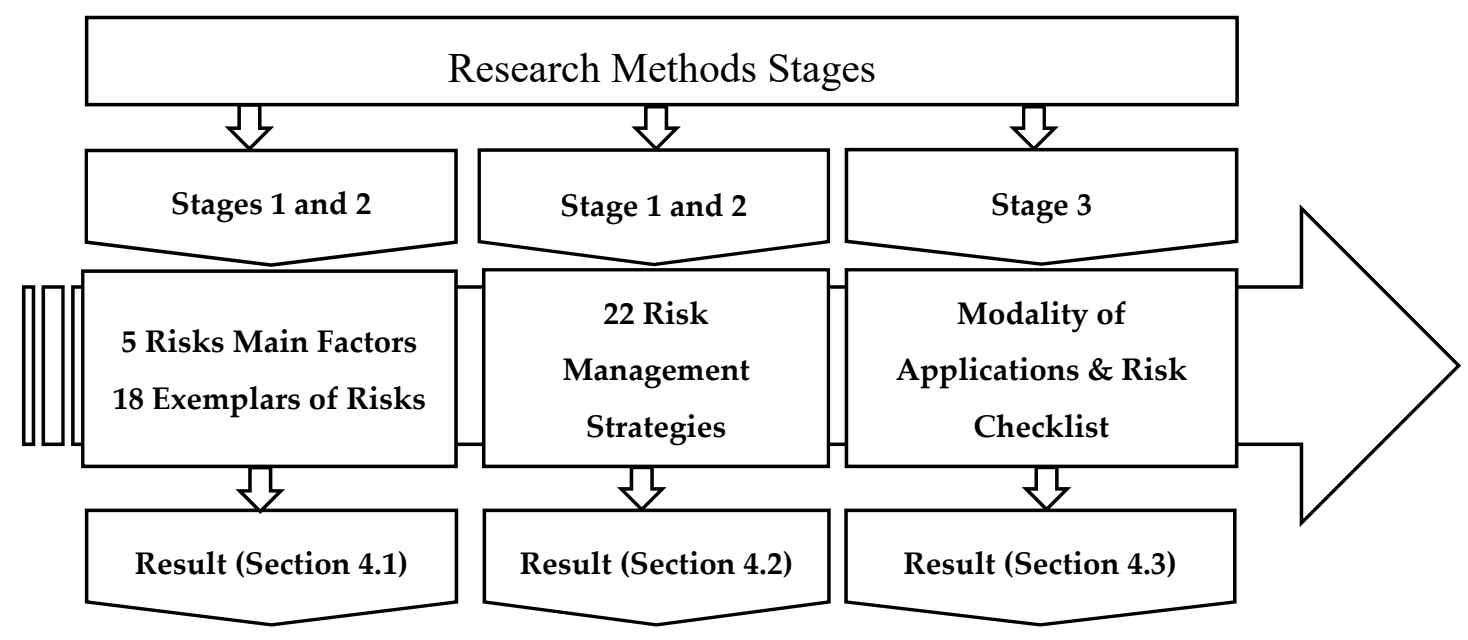

Figure 1. Result sections outlines.

\subsection{Gamification Risks and Risks Factors}

The analysis of the data gathered from the studies explained in Table 1 along with the observational study and the interviews shown in Table 2 were the main sources of the results presented in this section. Table 4 is providing a summary of the results and the research methods used to obtain them. As a first step, analysing the related literature together with results from our previous studies helped to design the first template of risk factors and a set of exemplar risks. In the next step, the studies in Table 2 were designed in order to verify the initial results from Table 1 and to come up with the final set of risk main factors and exemplar of risks from the real business workplaces. As a result, we identified five main classes of risk factors as summarised in Figure 2. These classes are related to performance, societal and personal, goals, tasks and gamification elements. The main risks associated with these factors are underlined in the text.

Table 4. Mapping the results to the research methods.

\begin{tabular}{ccc}
\hline Stage & Research Method & Main Results \\
\hline 1st Stage & $\begin{array}{c}\text { Secondary analysis of data } \\
\text { collected for previous works, } \\
\text { literature review, interviews }\end{array}$ & $\begin{array}{c}\text { Initial templet of risks and a set of } \\
\text { management strategies }\end{array}$ \\
\hline 2nd Stage & Observation study, interviews & $\begin{array}{c}\text { Final set of risks, risks factors, and } \\
\text { management strategies }\end{array}$ \\
\hline 3rd Stage & Two focus groups, interviews & $\begin{array}{c}\text { Management strategies modalities of } \\
\text { application, stakeholders, checklist }\end{array}$ \\
\hline
\end{tabular}




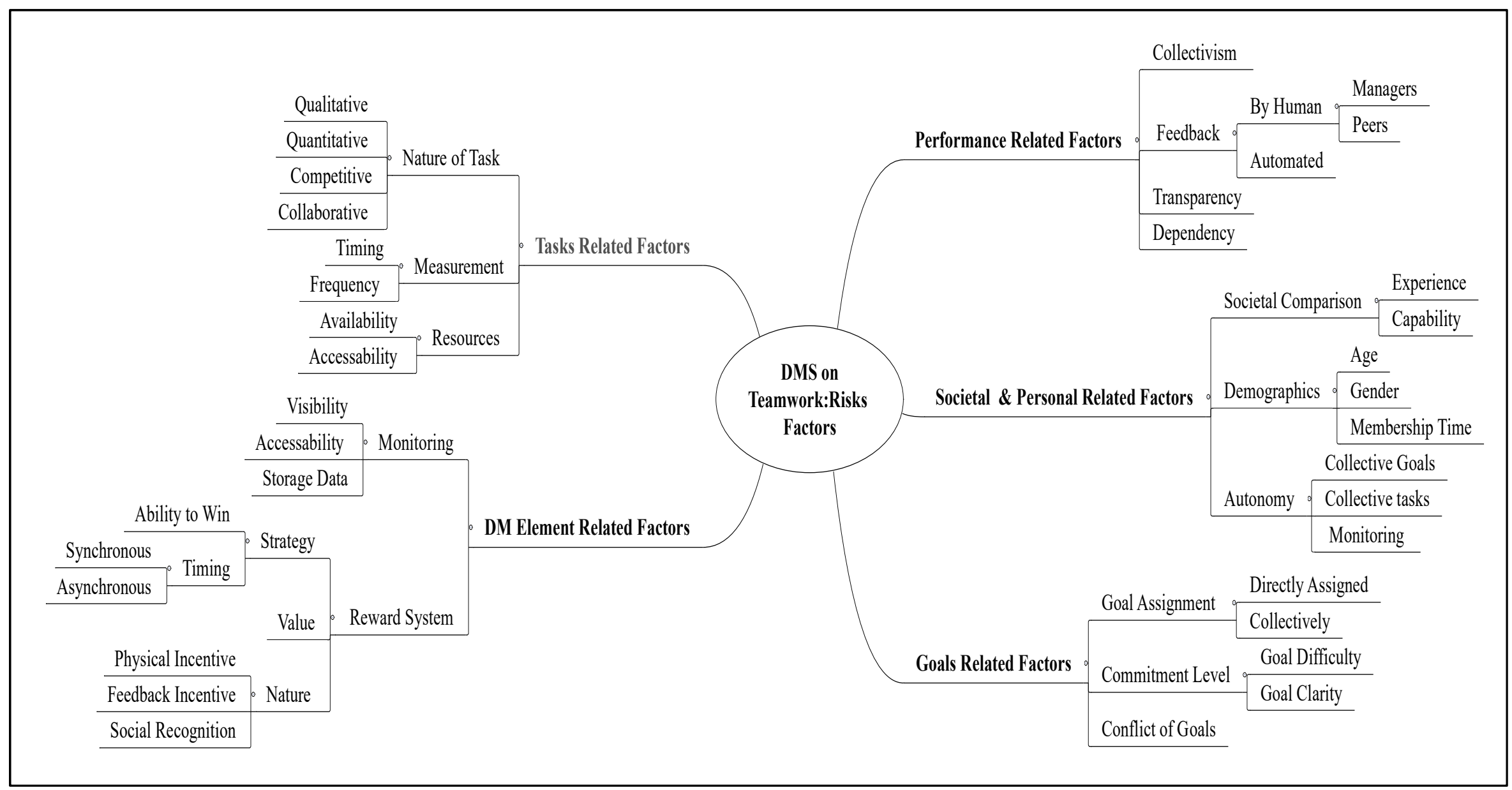

Figure 2. Conceptualisation of Gamification Risk Factors to Teamwork. 


\subsubsection{Performance Related Risk Factors}

Performance is defined as "scalable actions, behaviours and outcomes that employees engage in or bring about that are linked with and contribute to organisational goals" [40] (p. 216). Performance monitoring is commonly used in organisations and has become widely pervasive with the aid of digital tools [41]. While a principal aim of gamification in an enterprise context is to increase staff performance, we found that this could lead to the following four main risk factors.

Performance Collectivism. Gamification elements, using rewards and feedback on the collective performance of staff, might have a negative influence on the level and quality of collaboration among them. Risks of free riding occur when some team members tend to perform less well as they receive rewards equal to others, regardless of their individual performance. Moreover, risks can be seen when some team members work only to meet the minimum task requirements without paying enough consideration to the level of quality of their work. Although the collective performance is needed for the sense of teamwork, these situations might affect the work collaboration and create risk in the workplace. In other words, solving such issue requires mitigation techniques which support a sense of auditing and checking strategies, rather than just avoiding collective performance tasks.

Performance Feedback. Feedback related to staff performance is a vital element of motivation, but it may also contribute to risks related to the quality of the teamwork environment. An example is a badge or an avatar representing the current status of work quality. The main risk here is the misjudgement of performance. In a teamwork environment, feedback can be based on self-comparison, i.e., comparing performance to one's own performance in the past, peer-comparison feedback, i.e., comparing a person to others in their team, or collective-comparison feedback, i.e., comparing teams' performance to each other.

Our results showed different preferences about receiving performance feedback which shall be met to avoid risks. The source of feedback is the primary factor. Feedback can be generated by managers based on human-made judgments or software based on algorithms. Feedback from a human is seen to overcome the limitation of machines of measuring performance only based on the software-monitored performance indicators, e.g., number of calls answered but without looking at the quality and difficulty of the issue. Feedback from machines would suit the performance of tasks which are uniform and quantity based. It can also be preferred when objective measures are provided, e.g., customer feedback and rating. Manager feedbacks can reduce risks when the task is quality oriented and uneasily measured by machines. To reduce these risks, a blended approach can also be needed, e.g., when managers moderate the judgments made by the software. Besides the perceived misjudgement in feedback, clustering groups is another risk which can stem from feedback based on collective performance in teamwork. Top performers members may form their own teams and win. Moreover, feedback can be associated with past performance, e.g., examples of the previous behaviour in a task which might help to ease the future work [42]. In a teamwork environment, receiving such type of feedback may have a negative influence on staff that recently joins the team. It may lower self-esteem or make them less motivated to engage with the team.

Performance Transparency. Transparency of a gamification system collected performance data, and judgments derived from processing such data, manifests itself in three ways; transparency to managers, transparency amongst acquaintances involved in or doing the same task and, finally, transparency with staff in the department or the organisation. Although performance transparency can mitigate risks about perceived unfairness and conspiracy, it seems that several ethical and moral concerns arise as a result of it [43]. There is a fine line between transparency as an enabler for trust in a gamification system and as a counterproductive comparison and pressure tool. For example, disclosing the number of calls answered and points earned by each agent can increase competition and improve performance but, at the same time, it may convert sales representatives to set their performance goals based on other staff performance rather than the company target. In the observed call centres, performance transparency causing staff to be featured on the leaderboard was not appealing to those who "did not like to be known as a top performer because others start to come to their desk and keep asking help". 
Transparency can increase the chance of anchoring bias among workers since it may spark the idea of seeing other's performance as a benchmark rather than a reference to help to realise personal strengths and skills aiming to employ them in better-suited tasks.

Performance Dependency. The likelihood of risks in a teamwork environment increases when gamification techniques monitor and reward staff performing tasks which cannot be fully achieved independently. In the case of our call centre observations, risks of frustration and tension increased when an agent from the customer calls team needed support from a busy IT team to close a customer complaint. This can give rise to bribes, where a person may need to offer something in return to their dependees to get the gamification reward [5]. To address this issue, the gamification mechanics should be designed in a way that recognises potential deadlocks with the ultimate goal of not affecting the level of assistance required between staff.

\subsubsection{Societal and Personal Related Risk Factors}

Societal factors relate to the effects of a behaviour or a perception in relation to other staff, while personal factors relate to traits and inherent characteristics of staff.

Societal Comparison. Comparing staff with different capabilities and experiences, especially on a competitive basis, is a significant risk for a gamification system. Lowering self-esteem and intimidation are examples of such risks. The comparison is an essential game mechanics. Its design should seek to incorporate the differences between subjects, and measure their progress in a relative way.

Demographics. Age, gender and team membership duration influence acceptance and attitude towards games and gameplay applied to teamwork [44,45]. For instance, participants in our study mentioned that "being with younger members in the same teamwork is frustrating, as they have better ability in digital techniques and their chance of winning the reward is higher". It can further be argued, that the appreciation of rewards of social benefits and collaborative nature, and those of competitive nature, can differ by gender [46]. Finally, the novelty effect of gamification technology means it can be initially exciting for new members, but become less useful for those with more extended experience [47].

Autonomy. Being obliged or pressured to be part of a gamification system in a prescriptive way can be detrimental [43]. Self-determination theory states that autonomy is one of the human psychological needs [48]. Flexibility and freedom of choice in tasks and goal allocation, primarily when performed collectively within groups, can encourage better teamwork collaboration, and reduce the likelihood of conflicts. For example, we identified in our study that pre-defined steps in a gamification tunneling based technique, e.g., progress bar with tasks and milestones, might be preferred by staff who prefer serialism. Alternatively, staff who have higher autonomy and prefer holism may experience such monitoring and feedback as negative reinforcement.

\subsubsection{Goal Related Risk Factors}

The results identified that some risks to the teamwork environment can be related to the goals factors, such as main gamification goals (e.g., increase staff performance) or personal staff goals (e.g., winning rewards).

Goal Assignment. While goals in teamwork can be assigned directly (by a manager for instance) or collectively (among team members), assigning them might affect the motivation to perform a task. For instance, "the directly-assigned goals make staff working like a machine and affect their creativity in a task and the interest to perform it". On the other hand, in collective goal assignment, staff with high self-efficacy and confidence in their skills and ability to reach goals have more influence in setting goals for the team [49] and this can result in stress to others afterwards. Staff with high self-efficacy may prefer more challenging goals than staff with lower self-efficacy [49]. Hence, managing the participation in goal setting is a key to set participatory goals.

Commitment Level. Staff with higher self-efficacy tend to be more committed to assigned goals than those with lower self-efficacy [49]. In teamwork, a lack of commitment to goals is strongly related to the level of performance in a task [50]. This is affected by two factors; goal difficulty and goal clarity. 
Goal Difficulty. This indicates "a significant drop-off in performance as goal commitment declined in response to increasingly difficult goals" [51] (p.70). Moreover, there is a contradictory relationship between goal commitment and goal difficulty [51,52]. Our study showed that in gamification teamwork where goals have been set collectively or via managers, the possibility of staff facing difficulties or discomfort in achieving goals is high. Consequently, such difficulties might affect their engagement with the team and create risks such as lowering self-esteem and deviation from the primary goal.

Goal Clarity. This refers to the metrics and steps required for goal achievement. Lack of clarity is another source of risk in gamification which might have an impact on staff's ability, intention or desire to commit to a goal. An example of this would be the case of adding a progress bar to motivate a call centre agent to help a client in completing an online registration form, but without clearly explaining why the client is given the help, or what system is used to evaluate the outcome.

Conflict of Goals. One of the primary reasons for having ethical and well-being issues in gamification systems is its potential conflict between stakeholders interests [53]. In a teamwork environment, conflict of goals can occur when a goal is collectively assigned. This might affect the gamification system and cause staff to have a lack of engagement or a lack of interest in a task, failing to achieve the system goal. A participant in our study stressed the conflict between being "on probation and having to perform well to get the job permanently, and being with staff who already passed their probation and have different goals in the system". This can have an effect on the performance, such as needing to work extra hours and doing other staff tasks who are not under the same pressure, to appear on the leaderboard and prove efficiency.

\subsubsection{Task Related Risk Factors}

Engaging staff more successfully with a task is a key objective of a gamification system. Our results indicated gamification risks on team working stemming mainly from the characteristics of the task being subject to gamification techniques. For example, applying a gamification element such as a leaderboard - which follows a competitive ecology - to a collaborative task could have a negative impact on the intra-group relationships. In the following section, we explore three task-related risk factors about gamification in teamwork.

Nature of Task. A quantitative based task might introduce a risk such as reduce the quality of the work. For example, customer satisfaction may suffer if the reward is based on the number -rather than the quality - of customer calls. In quality tasks, the risk can be seen by the lack of clarity in setting task specification and requirements. In other words, one way to judge staff performance in quality based tasks is the systematic performance judgment based on electronic monitoring or feedback; this might increase the chance of unfairly judge staff performance, e.g., using predesigned automated measurements. Our participants argued that: "it is unfair to be judged only based on monitoring customer calls", implying that the work required cannot be accurately reflected solely by the actual effort required. They added: "the quality might be affected by a variety of elements like the level of difficulty and clarity in customers' requests as some are easier than others".

Also, risks might also occur if the task is of a competitive nature. Our analysis suggested that adding a gamification element to a competitive task can still affect the required level of collaboration among staff in the work environment. For example, in the call centre, staff may choose not to share a good solution for common customers issue with their colleagues to increase their chance to uniquely and efficiently solve more customers complains and win the reward. Similarly, risks also can occur when adding a gamification element to a collaborative task. Our study indicated that a situation such as social loafing, where individuals reduce their effort when working with a group and rely on others, has a high chance to appear if a collective task is motivated using inter-group competition.

Measurement. Measuring staff performance is essential to decide on rewards and feedback provided through gamification elements. Failure or limitation in such measurement can lead to side-effect on the teamwork environment. Two main factors are duration and frequency. 
Timing. The real-time ability in gamification elements to track staff performance and send real-time feedback makes the duration of the measurement a source of risk, e.g., unfair judgement. For instance, if the measurement of staff engagement in answering a call is based on real-time voice analysis, such as the level of comfort of the client and the friendliness of the call agent, this might lead to unfair judgments. The staff could be affected via various elements, e.g., difficult customer or inquiry during the performance measurement duration in such motivational technique which might cause unfair judgment of their engagement in a task. For instance, one of our participant argued that:" judgment based on real-time observation of our performance might be affected by reasons like difficult customer or issue which could increase the possibility of bias".

Frequency. Some staff may be more motivated by a daily performance report, while others would prefer it at the end of the task, as evidenced by one participant who stated: "I prefer to be measured on a monthly basis to be motivated more as I might feel frustrated if I know the result before, like based on weekly or daily results". Hence, having both kinds of staff on the same team might have adverse effects on the team.

Resources. The availability and accessibility of resources are essential factors which assist staff in performing tasks more effectively. For example, LiveOps, an application for online call centres, facilitates the real-time recording of customers' personal details. Hence, in competitive teamwork environments, where staff compete to win rewards, access to such resources plays a vital role in both individual and team performances. As a result, careful consideration is needed to avoid introducing unwanted bias which could affect staff motivation. In the call centre observed, it was noticed that some tasks required external resources, i.e., resources from another, potentially competing team. This made the possibility of winning the gamification reward dependent on resources from others, which affected the gamification system and created risks. One participant in the call centre commented that "some tasks required external resources from others which might affect the competition". Similarly, in such situations, where there are team metrics and team rewards, the likelihood of other negative behaviours such as work intimidation is increased.

\subsubsection{Gamification Design Related Risk Factors}

Gamification elements refer to those motivational techniques which can be added to the environment to engage, motivate, and monitor staff involvement in the workplace, as well as to increase their engagement and achieve business goals. Commonly used examples of such elements are points, leaderboards, badges and missions. The digital nature of the motivational elements adds more effective features such as real-time monitoring and feedback, and tractability and traceability of staff's performance. However, the gamification element also introduces risks, especially around the lack of validation and implementation strategies. For example, in the call centre observed, some staff continued to work without taking breaks, due to their perception that their performance-as shown on the leaderboard-was being scrutinised by other staff in the department. This might have a negative impact on the quality of their work as well as their well-being. Below, we discuss the two main risk factors we identified about the gamification elements.

Monitoring. Monitoring is an essential mechanism of most gamification elements which support the enhancement of staff performance. It can help staff to engage more in a task by regulating their performance or behaviours. However, monitoring can also have negative consequences in a teamwork environment, due to the following factors.

Visibility. It was noticed in the call centre observed that some staff had concerns regarding what would be visible to colleagues, either in the same or in other teams. For example, displaying the number of calls each team member has answered could impact the coherence of the group via dividing staff into new intra-groups based on their performance in a task [7]. Staff preferred their current performance to be visible to their managers or to themselves only, with the choice to share it with others. 
Accessibility. In a gamification system, decisions are made based on information gathered from the environment. In a teamwork setting, the accessibility of staff information in the monitoring technique might have a negative influence on the teamwork. For example, one agent in the call centre commented: "I prefer to have the ability to decide what the system can access regarding my personal information and also what my team members are able to access". Risks such as infringe staff autonomy can result from monitoring staff as they perform a task. For example, a supervisor in the call centre mentioned that they could access and monitor staff calls at any time. Some staff in the call centre agreed that they "prefer to know the accessibility time and the sort of information that has been collected".

The Storage of the Data. The staff could have concerns about the type of information stored on the system and the access control to such information. In a teamwork environment, a risk can be seen when performing competitive tasks, where teams might have access to data stored by other teams which might have a negative effect on the gamification system, i.e., ineffective competition. For example, in a fitness application where people are motivated by comparing their performance with peers, making the stored history available to others might affect the competition and kill the joy of the system.

Reward System. The primary motivator of most gamification elements is the reward mechanism. A reward system is another essential factor of the gamification that needs careful consideration to avoid adversely affecting the teamwork. Within the workplace, the gamification reward takes the form of physical rewards, feedback, or public recognition. The reward might be a source of risks in a gamification system due to the following factors.

The Strategy. Staff have a variety of preferences regarding how they want to be rewarded, which makes the strategy a potential risk factor in a teamwork environment. The strategy of the reward can be seen as a source of risk when introduces a sense of perceived exploitation in the workplace. Exploitation can occur when staff feel that their extra performance and quality of work are not rewarded. For example, this can happen when the reward strategy in place only rewards the best performance. It would be preferable, in such circumstances, to have a gamification strategy which recognised everyone's performance, and hence, supported teamwork.

The Ability to Win the Reward. Staff with low self-esteem might have difficulty to participate in tasks in teamwork when the ability to win the reward is high, which could have a negative effect on the coherence of the team. In the call centre observed, staff could be classified into two categories, those who preferred to be motivated to win the reward using a challenge, and those who found it a source of obstruction. Mixing both types of staff in the same team or same competition might affect the system and create a risk such as lack of group cohesion in the workplace.

The Timing. A reward in a gamification system can either be synchronous or asynchronous. In real-time, the system allows managers to provide synchronous rewards, such as real-time feedback. This can happen when the required goal of the task is achieved, even before the end of the task time. One example would be answering the target number of calls before the end of the week or month. In the call centre, some staff stated that they: "prefer to be rewarded after finishing the task not to lose my motivation". However, a participant mentioned that "I sometimes need extrinsic motivation while performing a task to increase my intrinsic motivation". In teamwork, especially in competitive tasks, receiving synchronous feedback might affect the quality of the work negatively, especially when staff feel they have little chance of winning the competition.

The Value. A low-value reward might demotivate staff, limiting their engagement with a task, and affecting their quality of work. The value of the reward should reflect the actual effort staff contribute to a task. In teamwork, for collaborative tasks, the collaboration might be affected when some staff are less motivated to participate in the task due to their perception of low-value rewards. The overall finding indicates that the value of the reward is recommended to be heavily connected to the level of performance staff required to win the reward, to avoid the risk of reducing motivation.

The Nature of the Reward. This can have different forms, e.g., physical reward, feedback, or public recognition. In the call centres observed, all of these rewards were used to motivate staff. 
The impact of the nature of the reward is heavily connected with the personality of individuals. The differences in staff preferences about the nature of reward might cause a risk in teamwork effectiveness, which can, in turn, affect the achievement of business goals. Some agents commented that "we feel more motivated to participate in a task with physical rewards rather than other types of rewards". Risks such as negative participation might occur in the system applied in teamwork when some members are less motivated as a result of the nature of the reward.

Table 5 summarises the discussed risks and classifies them under four general categories based on their nature and their related effect. This classification was also refined with participants in the focus group using card sorting technique.

Table 5. Risks Main Categories.

\begin{tabular}{cr}
\hline Main Category of the Risk & Risks \\
\hline Ethical Related Risks & Preserved exploitation, Bias, Work intimidation \\
\hline Well-being Related Risks & Lowering self-esteem, Negative pressure, Counterproductive Comparison \\
\hline Productivity Related Risk & Meet the minimum requirements, Lack of engagement, reduce task quality \\
\hline Performance Related Risk & $\begin{array}{c}\text { Free riding, Social loafing, Bribe for exchange, Clustering groups, } \\
\text { Performance misjudgments, Novelty effects, Deviation from goal, Kill the } \\
\text { joy, Infringe autonomy }\end{array}$ \\
\hline
\end{tabular}

\subsection{Gamification Risks Management Strategies}

One another focus of the studies in Tables 1 and 2, especially in the experts' interviews, was to figure out some management strategies for the identified set of gamification risks. The analysis of the gathered data was the main source of the result proposed in this section. Table 4 is providing a summary of the results and the research methods to obtain them.

In this section, we present another focus of our research, gamification risks management strategies. The identified risks were used to design interview questions and focus group materials in order to propose strategies which could help to manage these risks. The strategies are grouped in three classifications based on their purpose of use in order to manage gamification risks on teamwork environment. Table 6 shows these strategies and their main purposes of use in the gamification system.

Table 6. Management Strategies Main Categories

\begin{tabular}{cc}
\hline Attribute & Strategies \\
\hline $\begin{array}{c}\text { Setting up Agreements and } \\
\text { Informing Participants }\end{array}$ & $\begin{array}{r}\text { Commitment, Common ground rules, Facilitator, Voting, Get everyone } \\
\text { involved, Norms, Round robin }\end{array}$ \\
\hline Checking and Reporting & $\begin{array}{r}\text { Auditing, Member checking, Peer rating, Random monitoring, } \\
\text { Self-assessment, Storytelling, External party, Regular meeting, Managerial } \\
\text { level monitoring, Transparency, Anonymity }\end{array}$ \\
\hline Appreciation and Controlling & $\begin{array}{r}\text { Reward for helping others, Acknowledgment of individual efforts, } \\
\text { Non-contentious bargaining, Rotation sensitivity }\end{array}$ \\
\hline
\end{tabular}

\subsubsection{Management Strategies for Setting up Agreements}

We found that some strategies could be managed and implemented at the design stage in order to increase the acceptance of the system and inform staff on the work ethics. This could be achieved by running negotiation sessions to share ideas and ask all stakeholders (e.g., managers, supervisors, project leaders, agents and IT designers) to participate in decision-making session. 
- Get everyone involved: this strategy could encourage multi stakeholders in different roles and responsibilities or their representatives to participate in a discussion session to decide and draw behaviours, rules and penalties for the gamification workplace.

- Common ground rules: this strategy is based on deriving and enforcing rules that articulate the set of acceptable behaviours in relation to gamification system, in order to facilitate the development of the use of the system within the organisation. Examples of such rules include showing respect for others, appropriate ways in which to express oneself, allowing everyone to 'have a say', openness to different views and confidentiality. This would help to manage and facilitate the work environments and defining the acceptable behaviours.

- Facilitator: this strategy could play an important role in facilitating the design sessions of the gamification system, including running negotiation sessions, helping people to understand the objectives, and assisting participants to set the common rules of conduct in an effective work environment supported by gamification elements. Moreover, the facilitator is responsible to manage the voting strategy in order to reach agreements.

- Voting: this strategy could help to reach a decision in a facilitated session. When multiple choices are available amongst stakeholders in the design sessions, the facilitator could use a voting technique to try to meet the concerns of team members in a democratic and more acceptable style.

- Round robin: this strategy could facilitate the discussion by allowing the discussion to pass between participants and ensure equality and fairness during the session. This would help to maximise the ideas amongst participants involved in the session and thus maximise the acceptance of the gamification system in the workplace.

- Norms: this technique is based on having a clear understanding of what the organisational culture is, e.g., normal social behaviours. This could help to reduce the likelihood of negative effects within rewarding system environments. For example, an organisation may have a norm of senior managers publicly acknowledging successes of team members in monthly team meetings. A new gamification based reward system such as a leader board may aim to serve the same basic function of highlighting success within the team, but the departure from the previously established norm of face to face social approval may cause resentment in team members.

\subsubsection{Management Strategies for Auditing and Reporting}

These strategies could help to observe the workplace and prevent or alleviate some risks from occurring. The observation strategies can take different form, which could help to increase the chance for better management in the gamification workplace.

- Auditing: means checking individual performances, e.g., giving a quantifiable task and assuming people will also respect quality. Although the auditing technique can help to resolve negative effect on teamwork, one practitioner said "it should be used in a very careful style to prevent introducing another conflict or side effects". Auditing technique is the core or the umbrella technique of the following management strategies.

- Random monitoring: the idea of this technique is to keep staff aware that their performances might be monitored at any time. The random monitoring either can be implemented automatically by sending regular performance reports from the gamification system to managers or supervisors or by regular inspection of the results by the responsible stakeholders. Moreover, the customers can be also involved in the random monitoring process by using "secrete shoppers to evaluate the performance and the provided services".

- Peer-rating: this technique means that colleagues can rate each other's efforts and might be checked at any time to avoid a biased evaluation.

- Managerial level monitoring: in this strategy managers take the responsibility to check workers' performances in gamification workplace. This strategy can be applied separately or after another inspection strategy in order to refine the results and ensure complete and fairness. 
- Self-assessment: users assess their own performances, and this might be checked by managers at any time. This strategy aims to give individuals the responsibility to assess themselves. This can help them to evaluate their engagement with the team and to remain updated about their performance. This can help them to keep their performance at the acceptable level and to compare it to other team members.

- Regular meetings: involving teamwork members in regular meetings, e.g., weekly, monthly or annually would help managers to remain updated with the current use of gamification system. Our participants mentioned that "we need to keep informing our managers regarding the difficulties and other unexpected issues affecting our performance". The regular meeting can also benefit from applying other management strategy such as being transparent about the performance level compared with others, asking for self-assessment and starting the discussion of the performance level from that to make the staff more informed and engaged in the meeting.

- Transparency: this strategy means allowing everyone to see everyone's performances in the gamification system. Although some participants involved in our study agreed on the importance of this strategy to resolve gamification negative effects, others mentioned that "it should be designed carefully to avoid clustering high performances workers and those of the lower performances". This strategy needs to be managed and designed carefully and side effects need to be considered fully before making final decision.

- Anonymity: the core idea of this strategy is to give opinions or ratings of colleagues or managers in an anonymous way. This could help make the work collaboration environment open and coherent. For example, this strategy could help when risks occur in the team because the individuals' contributions are not measured. Anonymity in peer rating would encourage team members to rate each other's and performance related risks will be managed.

- External party: this strategy proposes to use an external authority or expert to check workers' performances and to resolve or suggest solutions for negative effects which might arise in the workplace. This can help when managers find it difficult to manage risks internally. A participant mentioned that it would "help to improve the performance of the group because if the inspection comes from the external authorities then I think everybody would be happy with that".

- Story telling: the core idea of this strategy is to identify negative effect by asking people to present a situation in a story. A manager involved in our study noticed that "when we have a conflict in our company I sometimes go out for walk with some of my staff and ask them to tell the situation in a story, this can help to determine the source of the conflict". Identifying the source of the risks is the core element in order to manage it.

\subsubsection{Management Strategies for Appreciation and Controlling}

Appreciation and controlling strategies are meant to prevent negative actions by encouraging and rewarding positive behaviours. The controlling strategies are mainly meant to control actions and prevent negativity to occur in the workplace.

- Reward for helping others: this strategy is related to prosocial theory [54], in which users can be rewarded for supporting others. This could be used to encourage collaborative teamwork such as by rewarding workers at the top a leader-board when they help their lower performing colleagues. This strategy can help to manage risks in relation to collective performance in a task e.g., social loafing and free riding.

- Acknowledgement of individual efforts: in some gamification situations, negative effect on teamwork might arise when individual efforts are not equal. This could arise when some workers rely on others to finish a task and is based on the concept of social loafing, so this strategy could help to inspire individuals to engage in group tasks to completion. 
- Non-contentious bargaining: to manage the work environment when risks occur, this strategy encourages team members to control their emotions in a professional way, such as by counting to ten before taking an action, or writing down their concerns calmly and carefully in an email [55]. This strategy can be used to reduce negative effects of gamification such as some sort of exploitation in the rewarding systems. For example, a group leader may only acknowledge top performing members of a group, via badges and status, despite the remaining group members performing their roles adequately. By expressing their concerns in a calm and reasoned (i.e., non-contentious) manner the group members may be able to reach agreement with the group leader on how a gamification system can be changed to the mutual benefit of all involved [56].

- Rotations sensitivity: this strategy is based on allocating people randomly within the gamification system so that cliques and rivalries are not created. This could help to eliminate a negative effect caused by workers only supporting their close colleagues to win rewards.

\subsection{Management Strategies: Modality of Applications}

The results of the analysis of the data gathered from studies in the first and second stages were used to design the materials of the studies in Table 3. Two focus groups followed by ten interviews were implemented to explore six main phases in relation to the applicability of the management strategies proposed in Section 4.2 to manage gamification risks presented in Section 4.1: (1) the suitability of the management strategy to manage the risk (2) the side-effects of such application (3) the main purposes (4) the way to apply (5) the timing of applicable and (6) the related stakeholders. Table 4 is providing a summary of the results and the research methods used to obtain them. As a result, we identified different modality aspects in relation to the application of the management strategies for gamification risks in teamwork environments. Figure 3 provides a summary of the main results related to these aspects. The representation of modalities revolves around the following six areas:

- Management strategies Vs. gamification risks;

- Risk Management strategies: Side effects;

- Management strategies: application purposes;

- Management strategies: application styles;

- Management strategies: application time;

- Management strategies: Stakeholders; 


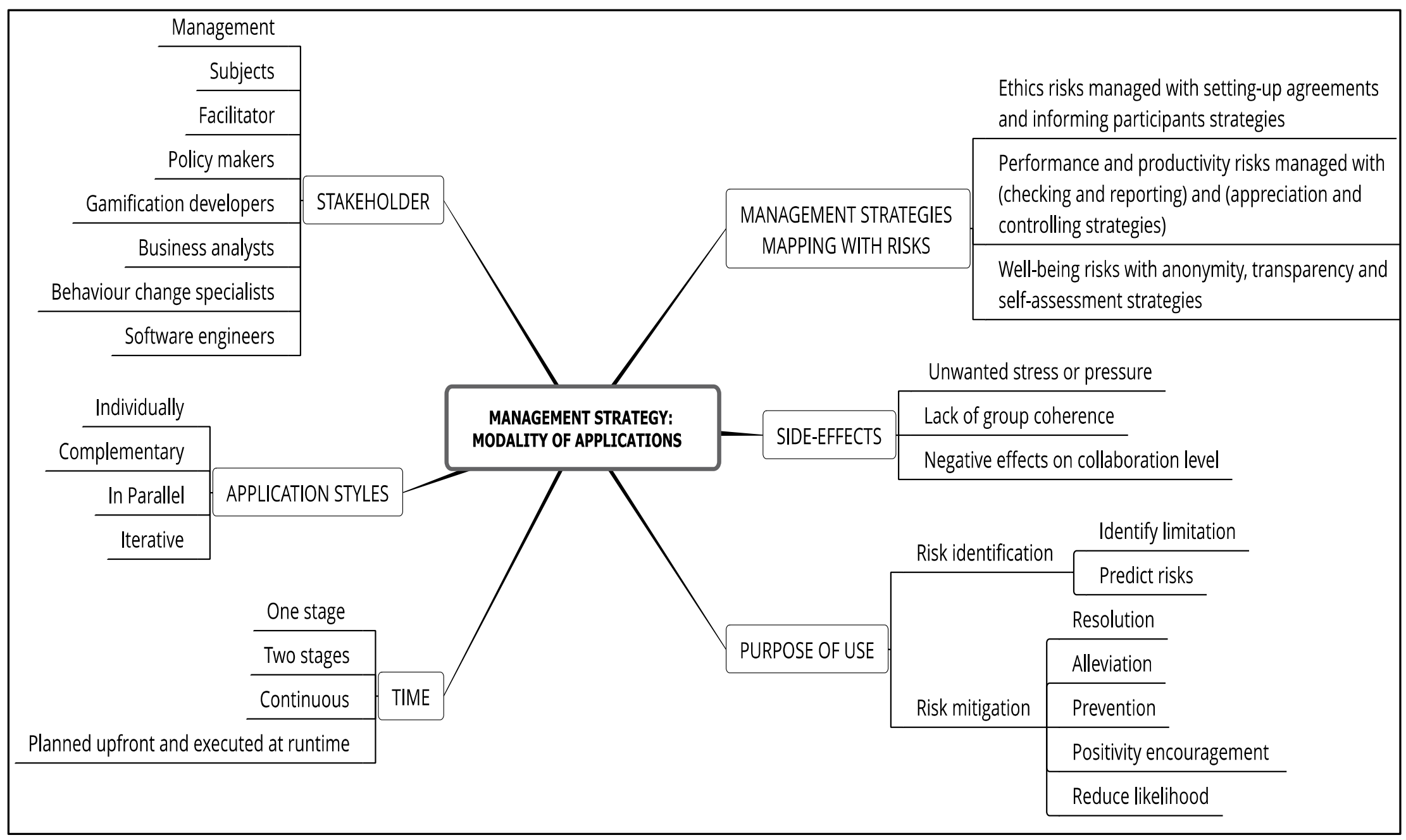

Figure 3. Gamification Management Strategies related modalities. 


\subsubsection{Management Strategies vs. Gamification Risks}

In the first focus group, a primary task was to match the families of risks with the suitable management strategies. The analysis of the results suggested three main classifications of the Gamification risks discussed in Section 4.1; ethics related risks, performance and productivity related risks and well-being related risks. Moreover, the analysis showed that the management strategies mentioned in Section 4.2 also revolve around three main categories; management strategies for setting up agreements and informing participants; checking and reporting strategies; and the appreciation and controlling strategies. The categorisations of the risks and the management strategies were developed to make the mapping feasible at a relatively higher level of abstraction given the fact that a more accurate mapping would require much more time for the participants and a larger scale study. As a convention alongside this section, risks are typed in underline and management strategies in italic.

- Ethics related risks. The analysis shows that ethical concerns become a primary concern with the adoption of gamification techniques in teamwork business workplaces. In Ref., [57] Berdichevsky and Neuenschwander argued that persuasive technology must not misinform people. In the risks proposed in Section 4.1, it seems that misinforming staff about the quality of work required to win a reward or the lack of information about the nature of the reward and the strategy to win it might cause ethics related risks such as preserved exploitation. Moreover, the misinformation about the transparency level in the system including the disclosure of the stored data to an external party or colleagues might also create ethical risks about work intimidation in a team workplace when people receive little information about how much of their performance and work behaviour is being inferred through gamification elements. Our research indicates that risks about ethics could be managed through strategies which maximise multi-stakeholders' participation at the design stage of the system in setting up agreements and informing participants about the various elements, e.g., work norms, guidelines and principles of the gamification and its governance. As a result, our participants suggested that strategies such as common ground rules, getting everyone involved, facilitator, voting, commitment, and round robin could help to maximise staff acceptance of the system and to make them well-informed.

- Productivity and performance related risks. These are mainly linked to the actual effect of gamification on the efficiency of executing a gamified task. About productivity related risks, it seems that gamification risks such as meet the minimum requirements, lack of engagement and reduce task quality could emerge in the teamwork places as a result of staff poor productivity in the gamified task. Also, performance related risks are linked to the way of accomplishing the gamified task. Risks such as freeriding, social loafing, bribe for exchange and performance misjudgements could occur due to group dynamics affected by rewarding groups collectively. The analysis found that the management strategies of risks related to staff productivity and performance should be defined, planned and agreed at the design stage of the system and implemented during the actual use of the system. At the design stage of the management strategies which support defining rules and making staff informed, e.g., common ground rules, get everyone involved, commitment, and round robin are useful for setting up the required level of performance, collaboration and quality of work. Moreover, strategies with a sense of checking and reporting such as auditing, member checking, peer rating, random monitoring, self-assessment, are useful to review and inspect the teamwork environment and to prevent or alleviate productivity related risks such as lack of engagement and meet the minimum requirements. Also, strategies with a sense of appreciation and controlling such as reward for helping others, acknowledgement of individual efforts, could assist to prevent or reduce the chance of risks about staff performance in the gamified tasks such as freeriding and social loafing.

- Well-being related risks. Gamification embraces various motivation triggers to enhance work environment quality and contribute to staff well-being. The results of our study indicate that risks such as lowering self-esteem, negative pressure and counterproductive comparisons are 
risks that relate to the adverse effects of gamification on both work efficiency and staff mental health and well-being. The competitive nature in most of the gamification elements and also the monitoring mechanisms can be seen as the main sources of such well-being issues in the gamified tasks. Our analysis suggested that strategies which could help to increase staff privacy such as, for example, applying anonymity in staff names or performance can help to manage such risks. Moreover, strategies which could help to make staff feel safe about how they are going to be judged in the system using transparency strategy or self-assessment would increase their willingness to participate in the system and reduce the negative well-being effects.

\subsubsection{Risks Management Strategies: Side effects}

Besides the benefits of the management strategies to mitigate gamification related risks, they may trigger further side-effects requiring further management or at least awareness. For example, a participant mentioned that "rotation sensitivity strategy can help to alleviate risk in relation to clustering teams based on staff performance in the task; however, such rotation might create a risk to the business by reducing the overall quality of work when good staff members do not fit their randomly allocated teams". Stakeholders involved in the decision-making to configure the application of the management strategy should consider side-effects and, at times, have to decide whether to accept the risk or the side-effects of managing it through a certain strategy. The main side-effects identified in the study are related to (i) disrupting group coherence (ii) introducing unwanted stress and pressure (iii) adversely affecting competition and collaboration. The three cases are explained through the following points.

- Transparency as a management strategy might help to manage risks about staff performance in the system. However, it may introduce alternative risks such as clustering staff in the teams based on their level of performance. Moreover, it may add additional unwanted stress to staff by showing them their level of performance compared to others although they may have different timing and styles of concentrating their effort.

- $\quad$ Peer-rating as a management strategy might help to prevent risks about staff engagement in a task. However, it might have a negative effect on the team coherence. A participant suggested applying anonymity strategy together with peer-rating strategy to minimise the negative effect peers-rating strategy might cause to the team.

- Anonymity as a management strategy might help to manage risks introduced to the teamwork as a result of the transparency in manager's feedback of team individual performance, e.g., announcing, in a call centre, that top performers got between $95 \%$ and $99 \%$ positive customers rating without naming them while such anonymous announcement sets up the expectation and benchmark for the group. However, it might have negative effects on the right level of competition for staff that are only privately acknowledged for their performance.

\subsubsection{Management Strategies: Purposes of Use}

Two main purposes of the management strategies were identified to manage gamification risks; identification purpose and mitigation purpose.

\section{Risk Identification Strategies}

Risk identification strategies are meant to specify threats and limitations in the gamification system. By using such strategies stakeholders including analysts and managers can identify risks or predict their possibilities to occur in the workplace. Participants suggested that strategies for risk identification could be applied at the early stage of gamification deployment or even design. They emphasised strategies such as get everyone involved and round robin could help to identify risks at the design stage by allowing all stakeholders to involve in the design session, e.g., participatory design (PD) [58], and give them an equal chance to comments on the design and logic. This could help to identify risks which can be introduced to the workplace as a result of the societal and personal factors, 
e.g., the identification of diversity of experiences and capabilities in the team and goals related risks factors e.g., goal difficulty as perceived by some team members.

When gamification is already running, strategies with a sense of revision and inspection such as auditing and storytelling about experiences with it could help to identify risks and sources of the risks in the gamified tasks in team workplaces. A manager participant stated: "I sometimes ask staff to tell the situation in a story to identify the risks or the reason behind it". Furthermore, random monitoring and managerial level monitoring are management strategies with a sense of risk identification by regularly checking the system results.

\section{Risk Mitigation Strategies}

This sub-section discusses various applications purposes of the management strategies to mitigate gamification risks on teamwork environment. Participants agreed on the following purposes to mitigate gamification risks;

- Resolution: the goal of these strategies is to resolve the negative effects of risks on teamwork. Strategies with a sense of exchanging interest and recognition could help to resolve gamification risks. For example, some performance related risks such as freeriding and social loafing can be resolved by applying strategies such as rewards for helping others and rewards for individual contribution.

- Alleviation: applying some strategies could help to reduce the negative effect in the workplace when it happens eventually and cannot be prevented. Strategies with the characteristic of intervention or mediation could help to reduce the severity of some risks. For example, anonymity strategy can help to alleviate risks of gamification teamwork as a result of unexpected transparency in staff performance.

- Prevention: strategies with the sense of setting up the agreement and making staff informed can be applied at the design stage of the system to prevent risks such as work intimidation and anchoring bias. This can be done by involving team members in the early steps of developing and configuring gamification and giving them equal chances to comment on how the system should be running and defining the acceptable behaviours this would help to prevent ethics related risks from occurring in the team environment.

- Positivity Encouragement: some strategies could help to encourage positivity even if risks are anticipated. Participants mentioned that strategies which have the characteristics of appreciation could help to encourage positivity in the team work and act as precautionary measures which enhance the work atmosphere and deter risk factors. For example, applying acknowledgement of individual effort strategy within the team could assist team members to increase their individual contribution in the tasks. Thus, the team coherence and level of performance in the gamification system would not be affected when goals and tasks are collective. Also, a participant emphasised, "acknowledge and reward agreement would help to increase team acceptance of such a system and encourage positivity". This means that some management strategy can be used not only to resolve the risks but also to motivate positivity and create a sense of fairness so that need to flag gamification related issues, if they happen, is minimised.

- Reduce likelihood: our analysis identified that understanding the risk factors and their sources could help to reduce the likelihood of the emergence of the risks in the team workplace. Strategies which support regular modification or updating monitoring and rewarding strategies could help to reduce the likelihood of some teamwork risks. For example, a strategy such as rotation sensitivity where staff should be allocated and moved randomly between teams could help to reduce the likelihood of risks related to societal and personal factors such as clustering around staff experiences and capabilities. 


\subsubsection{Management Strategies: Application Style}

There are different application styles for management strategies and each would depend on the type of strategy, risk and management styles. We found that the decision about these styles should happen after deciding the main purpose of the management strategy. We identified four main styles of applying risk mitigation strategies:

- Individually: refers to strategies which could be implemented separately to manage a specific gamification risk. Strategies which have well-defined objectives and clear directions can be run individually. Most of the observation strategies can be executed individually to manage the risks. For example, strategies such as random monitoring can be used for observing the work environment to check staff performance in the gamification system. The automated ability in the gamification system allows managers to set a fixed automated feedback based on automated measurement of staff performance and then run the strategy separately by itself to manage risks related to staff performance in the gamified task.

- Complementary: strategies for collecting agreements and setting up rules are candidates for being applicable collectively for effective risk management. When we get everyone involved at the design stage for giving all stakeholders a chance to comment on the design of the system or on the management strategy, we could also apply round robin, voting, facilitator strategies to ensure fair participation that would help for better results in the risk management and then apply commitment strategy on the final results.

- In parallel: refers to the possibility for some strategies to be applied in parallel with another strategy for effective risk management. The analysis shows that strategies which could also be used to reduce the side effects of other strategies are a candidate to apply in parallel with them, e.g., the application of self-assessment with random monitoring and the application of anonymity strategy with transparent strategy. A participant suggested that "it is always better to apply self-assessment with other checking and reporting strategy". Applying self-assessment strategy with other checking and reporting strategies could help staff to check their own performance before they are being judged or measured by others. This would help to make staff informed about their level of performance and try to maintain it before final judgments are made. For example, risks such as meet the minimum requirement and lack of engagement in a task could be managed using peer rating strategy. However, to minimise the side-effects of such strategy participants suggested applying anonymity strategy with peer-rating strategy to avoid creating tensions and affecting group coherence.

- Iterative: our analysis indicates that some risks can appear only after a while and due to reasons such as the novelty effect and also because of other personnel joining or leaving the team or changes in the management style and task types. Thus, random monitoring and rotation sensitivity both are repeatable strategies for better risk management even if there are low indicators of any risk. Risks such as novelty effect can be effectively managed with an iterative type of management strategies. Applying such management strategies could help staff to keep motivated in the system by rotating them to different teams with different motivation techniques from time to time. This would help to alleviate novelty side-effects. Moreover, as mentioned in Section 4.1 risks which can exist in the workplace as a result of factors such as, staff membership time in the team or staff with different experiences and capability in the same team can be managed with iteration types strategies.

\subsubsection{Management Strategies: Application Time}

Regarding time, the management strategies can be applied at different stages of the gamification system lifecycle. We identified three main classifications of implementation time.

- One stage strategies: we found that strategies with a sense of setting up agreements and informing participants suit to be implemented as one stage application. This could be 
implemented once in advance at the design stage of the system. Repeating them when new team members join is still possible, but this can be then seen as setting up the rules again for a new team.

- Two-stage strategies: refers to strategies which could be useful at the design time and also the runtime stages. Strategies with a sense of controlling or facilitating the application of other management strategies would suit a two stages application process. For example, a transparency strategy can be applied at the design stage where participant should be informed about everything related to the system e.g., the goals and the reward strategy. Also, it can be implemented at runtime stage where staff can be aware of their performance level captured by the automated monitoring.

- Continuous strategies: this refers to strategies which can be started at the design stage and continually implemented at the runtime stage. In particular, strategies with continuous benefits would be more helpful when they are being continually applied in the workplace. For example, the external authority strategy can be used at the design stage for the setup of an agreement process and also then be continually applied to supervise and review the actual implementation of the strategies at the runtime of the system.

- Planned in advance and executed at runtime strategies: there are situations in which some strategies could be decided, planned and agreed at the design stage as corrective measures and then executed at the right time at runtime stage for better risk management. Strategies which require prior decisions and agreements over the way of their implementations are suited for such type of application. For example, participants involved in the focus group suggested that to manage novelty effect risk, stakeholders involved at the design stage of the system could plan and agree on the way of applying rotation sensitivity strategy, e.g., when to move staff between teams and based on what.

\subsubsection{Stakeholders}

Stakeholders have been defined by Freeman as "all those identifiable groups or individuals on which the organisation depends for its survival, sometimes referred to as primary stakeholders: stockholders, employees, customers, suppliers and key government agencies" [59] (p. 300). In our research, stakeholders are people who should be involved in deciding and conducting the management strategies to identify and reduce gamification risks. In Clarkson principles of stakeholders' managements, it was argued that managers should listen, communicate with all stakeholders to take all of their interests and concerns into account in decision making process [60].

In this section, we identify stakeholders who should be involved in the decision-making session about management strategies for gamification risks in teamwork environment. One primary aspect of the focus group study, listed in Table 3, was to identify the stakeholders of the management strategies. The participants were given scenarios explaining various cases where gamification risks can emerge. Also, they were given a separate list of potential stakeholders which were proposed from related research $[7,61]$. Participants were asked to recommend and give their insights - either from the list or from their own perspective-about the stakeholders to be involved in each scenario in order to decide and configure the risk management strategies. Also, they were asked to recommend the main roles of the identified stokeholds within the decision-making session. Our analysis suggested that the set of identified stakeholders shall be engaged in a decision-making session to configure and decide the management strategies from the early stage of the gamification development process. Those stakeholders and their roles in the session are discussed in the following points and summarised in Table 7:

- Management: this can be done by managers, supervisors or project leaders. The role of the management stakeholders is to decide which of the other stakeholders should be involved in the decision-making session. Also they are responsible to ensure that the application of the management strategies would not have side-effects on the achievement of the business goals. In addition, our analysis suggested that management stakeholders are responsible to govern 
and guide the application of the management strategies during the actual implementation of the gamification system in the workplace. This includes deciding who is responsible to run the strategy e.g., peer rating and random monitoring, and how they should be implemented in the workplace. For example, they can specify when to use peer rating strategy and who should be rating whom within the team. Also, they should specify when the auditing and reporting strategy type requires applying external authority strategy to manage risks which cannot be managed internally. Some participants emphasised "the need to have the external authority to ensure fairness in the way of applying the observation strategies alongside with the management and supervisors". This is to avoid management bias.

- Subjects: this type of stakeholder is related to people who are meant to experience gamification and who are being affected either negatively or positively by its application in the workplace. Based on the business context of this research, the subject stakeholders are staff users. Their role in the decision-making session revolves around assessing the ability to achieve the goals of the gamified task in the work environment. Also, depending on business context and the given situation, they should participate in the identification process of gamification risks and cooperate with other stakeholders to better decide the application style of the potential management strategy to manage the identified risks.

- Facilitator: their main role is to facilitate the decision-making session and ensure the involvement of all stakeholder or their representatives in the risk elicitation and management sessions. They are also responsible to manage the voting management strategy if stakeholders agree to use such strategy during the sessions. At the end of the session, facilitator should ensure all stakeholders involved in this session should give their consents and commitments on the decisions made. Interestingly, some participants expressed that the facilitator role should not be played by the management stakeholders, but rather by an external party as a facilitator. This can help to maximise various participants' opportunity -especially staff- to fairly and openly add their insights in the design of the gamification elements and the risks management strategies.

- Policy makers: as discussed in Section 4.3.1, gamification ethical risks can be managed by applying management strategies which can help to make participants informed about the policies and the rules from the early stage of the system. As a result, policy makers should ensure appropriate measures in terms of the ways agreements are set up and participants are informed should to manage risks in relation to ethics in the gamification workplaces. Also, they should provide insights and recommendations on the legality of the modality of applying the checking and reporting management strategies. Our participants also reported that they should contribute on the risks identification process as well to identify risks around related aspects such as risks that might be introduced to the workplace because of the rewarding strategy or the performance measurement policies.

- Gamification developers: are people responsible for designing games or gamification elements. Their main role in the risk identification and management sessions is to provide insights regarding the negative effects of the application of the management strategy to the gamification system effectiveness and feasibility. They need also to be knowledgeable in game design methodologies and tools [61]. For example, a management strategy could entail measuring performance automatically where gamification developers shall assess the possibility to do that using current technology without disrupting users' experience.

- Business analysts: they are responsible to provide clear understanding on the economic costs of the application of the management strategy. For example, the cost of the regular application of external authority as a management strategy can be high and, hence, they can advise on the cost and the ability of that the organisation to cover the cost and whether to join this process with other existing processes such as external mentorship which may be already in place for staff.

- Behaviour change specialists: participants agreed on the need for a stakeholder with psychological knowledge to participate in the decision-making session. Their roles are to 
contribute on the identification of the expected behaviours when applying gamification elements and the behaviour after the application of the management strategy. Also, they can contribute on the risks identification process by identifying the predicted behaviours within the gamified task. This is important for the teamwork environment and expertise in social psychology and group dynamics would be essential.

- Software engineers: their role is to provide rich information on the possibility for some management strategies to be embedded within the design of the gamification system together with the enterprise information system and its business process. They can also advise on the feasibility and fitness of the application styles to manage gamification risks given the existing computing infrastructure and architecture. For example, they can contribute in shaping the way of applying automated random monitoring strategy and the automated managers' performance feedback on the gamification element in terms of frequency and granularity. Also, they can provide information regarding an alternative design of the gamification system when risks management strategies may not be possible without side-effects. For example, they may suggest leaderboards visibility to be one time only to avoid people constantly checking to see their rank and making negative comparison and work intimidation.

Table 7. Management strategies Stakeholders' Roles and Descriptions.

\begin{tabular}{|c|c|}
\hline Stakeholder & Role Description \\
\hline Management & $\begin{array}{l}\text { Managers, supervisors or project leaders who are responsible for } \\
\text { identifying other stakeholders to be involved in the risk management } \\
\text { decision-making session. Also, they are responsible about confirming the } \\
\text { process of running and managing the checking and reporting management } \\
\text { strategies while gamification is running. }\end{array}$ \\
\hline Subjects & $\begin{array}{l}\text { They are the people who are going to experience gamification in their job. } \\
\text { A diverse sample of such gamification users should be involves in the } \\
\text { decision-making session. Players' types (socialisers, free spirits, explorers, } \\
\text { achievers, players, disruptors and killers [62]) can be the basis for selection } \\
\text { in addition to diversity in ages, gender, capabilities and experiences. }\end{array}$ \\
\hline Facilitator & $\begin{array}{l}\text { This role refers to the people facilitating the sessions and the use of voting } \\
\text { management strategy if needed. Also, they should ensure equal and fair } \\
\text { participation of the various stakeholders involved in the session. It's } \\
\text { advised to select the facilitator from an external authority which has been } \\
\text { mentioned in Section } 4.1 \text { as one of the management strategy for some kind } \\
\text { of risks. This is to increase impartiality and openness in opinions. }\end{array}$ \\
\hline Policy makers & $\begin{array}{l}\text { They play a main role in management strategies regarding setting up } \\
\text { agreements and informing participant to ensure that the policies are } \\
\text { well-designed to reduce ethics related risks and be aligned with the overall } \\
\text { management strategy of the organisation in relation to quality assurance, } \\
\text { communication protocols, trust, transparency amongst roles and so on. }\end{array}$ \\
\hline Gamification developers & $\begin{array}{l}\text { Their role in the decision-making session is to contribute to the possibility } \\
\text { of the management strategy to affect the gamification system and the ability } \\
\text { to accommodate it in the design of the system. }\end{array}$ \\
\hline Business analysts & $\begin{array}{l}\text { They provide business-related insights on the suggestion and the } \\
\text { application of the management strategies in terms of their costs and } \\
\text { possibility to integrate with existing processes and procedure. }\end{array}$ \\
\hline Behaviour change specialist & $\begin{array}{l}\text { Recommendations about the effects of gamification elements as well as their } \\
\text { risks management strategies on people behaviours within a team workplace } \\
\text { and recommendations about optimising them. }\end{array}$ \\
\hline Software engineers & $\begin{array}{l}\text { To check the possibility of any solution to be part of the design of the } \\
\text { gamification system and its underpinning enterprise information system } \\
\text { and computing infrastructure and architecture. }\end{array}$ \\
\hline
\end{tabular}




\subsection{Checklist Tool for Supporting Risk Identification Process}

In this section, we elaborate on our previous results and provide a tool which could help stakeholders in the decision-making sessions to identify and resolve gamification risks. Our study indicated the need for such a tool giving the complexity of risks and their inter-relations to task nature and groups structure. In the literature, it is recommended to have multiple sessions conducted iteratively to allow for a comprehensive and continuous identification of gamification risks or possibilities of failure $[30,63]$. In this section, we propose a checklist tool which could facilitate the risk identification process and support stakeholders to identify risks and express their concerns in relation to the gamification system.

A checklist can be used as a risk identification technique which is commonly applied in the literature to identify software related risks $[35,63]$. In our research we identified that gamification stakeholders, especially staff who experience gamification, find it difficult to define their related risks. This is specially the case at the early stage of the system design where gamification has not been yet tried in real work. Thus, we propose a checklist tool presented in Table 9 to inform and guide the risk identification process and help stakeholders involved in the design sessions to identify, address and predict risks from the early stage of the system.

As mentioned in Ref. [35], the checklist as a risk identification tool can be developed based on identifying the main risk sources and through an iterative process with participants from related domains. Our proposed checklist in Table 9 is proposed based on the results of our extensive studies around the gamification risk factors (Section 4.1) and through an iterative refinement process with our participants who involved in the interviews and in the focus groups of this research.

The checklist is a risk identification tool which can be used during the decision-making session at the early stage of the gamification system design. Managers, subject stakeholders and facilitators should go through the checklist to determine the initial set of risks and their main factors. Each "No" answer to a risk item in the checklist means that a specific risk has a high chance to occur in the workplace. The risks are presented in the checklist table by a symbol (R) followed by its number. These risks are listed in Table 8 . The results can be then documented in a risk mitigation plan. This is followed by the process of the management strategies which proposed in Section 4.2 to discuss the suitable management strategy for the identified risks in order to eliminate their effects on the business team workplaces. Our future work will explore this second stage.

Table 8. Risks and their Symbols.

\begin{tabular}{cc}
\hline Risks Symbol & Risk \\
R1 & Free-Riding \\
R2 & Meet the minimum requirements \\
R3 & Performance Misjudgments \\
R4 & Clustering groups \\
R5 & Lowering self-esteem \\
R6 & Counterproductive comparison \\
R7 & Negative pressure \\
R8 & Anchoring bias \\
R9 & Bribe for exchange \\
R10 & Work Intimidation \\
R11 & Novelty effect \\
R12 & Deviation from goal \\
R13 & Lack of engagement \\
R14 & Reduce task quality \\
R15 & Social loafing \\
R16 & Infringe autonomy \\
R17 & Kill of the joy \\
R18 & Exploitation \\
R19 & Lack of group coherence \\
\hline
\end{tabular}


Table 9. Risk Identification Checklist.

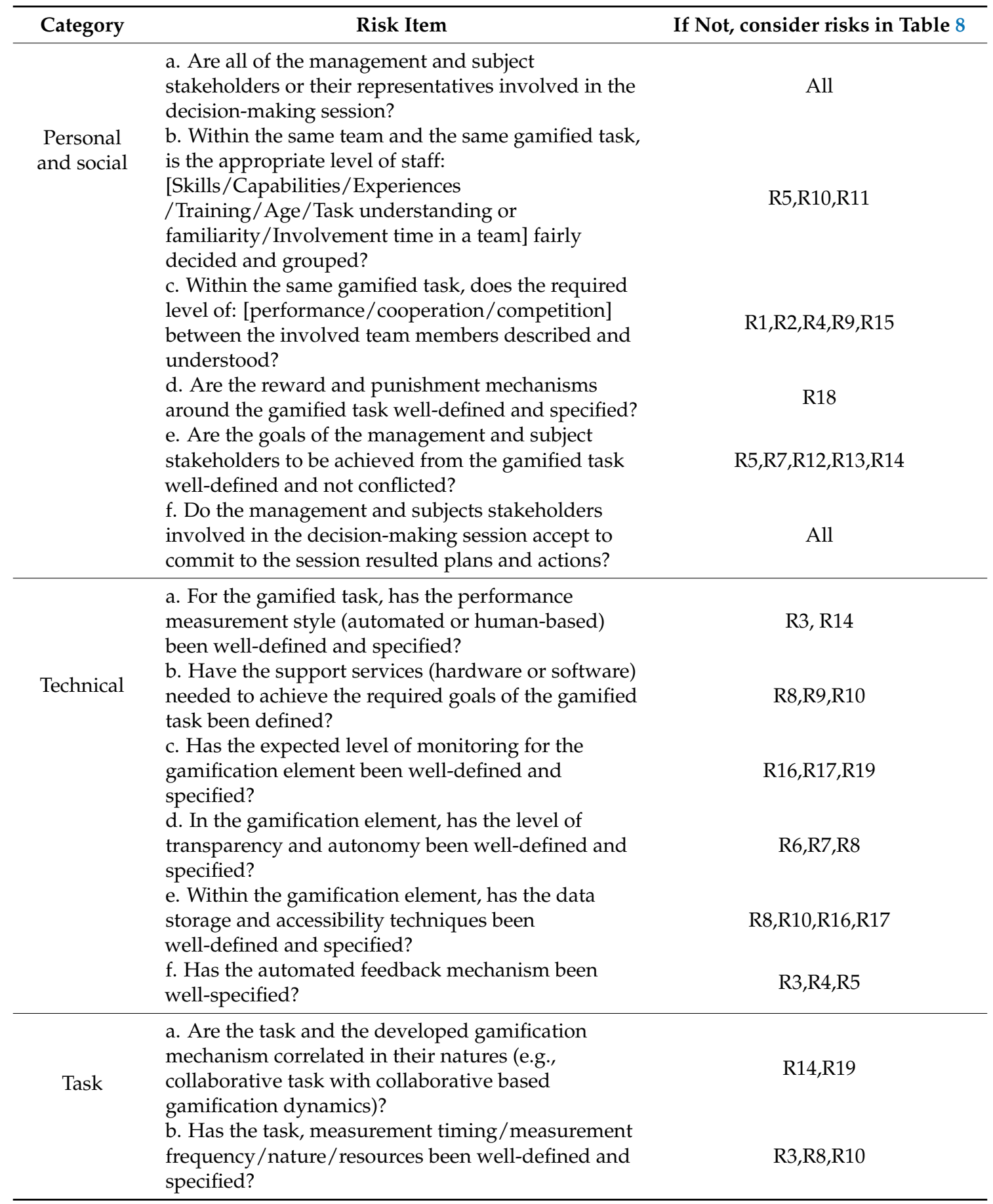

The risks (R) discussed in Table 9 are listed in the following Table. These risks and their main sources in the gamification teamwork environment have been discussed in Section 4.1.

\section{Discussions}

Despite the recognition of gamification risks in principle [5,43,64,65], there is little research on concretising such risks and their mitigation strategies. Our research explored gamification risks together with recognition of the social aspects (e.g., social structures and roles), dependency between actors, personality traits, tasks and goals. Also we proposed a taxonomy of gamification risk factors to give a more concrete view of them. Although we link the discovered risks to their main sources in 
the gamification system, we acknowledge that there was some overlapping in relation to their main sources in the system. This indicates the level of complexity in identifying and managing the risks of such systems and demonstrates the need for well-established risks assessment and elicitation methods. Our research therefore revealed the need for a systematic approach for gamification risk management within enterprise in general, and within teamwork environment in particular.

Related literature [35] and our participants' comments emphasised the need to examine the system where gamification is to apply as early as possible in the development process in order to manage risks starting from the analysis of gamification including the decisions of the tasks to be gamified, monitoring and performance management strategies and rewards system. Our analysis also suggests that risks management strategies cannot be separated from such analysis and should not be delayed until gamification is designed and integrated.

In Ref. [30] one of the common principles for engineering gamification systems is to have a continued monitoring to ensure that the system is delivering the required level of user engagement and motivation. Likewise, our results suggested to continually apply some mitigation strategies such as the random monitoring strategy under management responsibility with regular involvement of external authority. This will help to maintain the effectiveness of the system and reduces the chance of some gamification risks e.g., social loafing and free-riding.

According to Ref. [35], a primarily principle of designing gamification is to have a profound understanding of users, particularly of their goals and needs. Similarly, our results expressed the need to involve staff as a key stakeholder in the design stage of the gamification system in order to discover and address their related risks and involve them in the decision-making of the management strategies.

Participants involved in our interviews emphasised the need for careful and informed decisions to implement a management strategy to manage risk in the system especially when they integrated either transparency or autonomy features as this might destroy the whole system.

The risk identification process is seen as an iterative process to allow for a continuous discovery and determination of the gamification risks either at the design stage of the system or during the production time stage. Alongside with the proposed checklist for risk identification and management, we found in the literature other approaches which could support the decision in such process. For example, the Delphi method [66] is a well-known tool in information system research for identifying shortcuts based on several rounds of debates. However, the Delphi method is commonly presented in the literature for collecting experts' agreement on specific issues while our discussed checklist and its elements are meant for experts, managers, developers, analysts and staff. Hence, a different way of managing the debate and discussions would be required. There is a genuine need for such mixture of stakeholders given the nature of gamification and its inherent relation to how staff perceived it.

\section{Conclusions and Future Work}

In this paper, we argued that gamification in enterprises shall undertake a risk assessment and management process to cater for its potential side-effects on teamwork. To bridge the gap, we took the first step towards proposing a theory-informed method of gamification risk assessment. To form the basis of the method, we built upon and extended our previous works on management strategies for gamification risks and the taxonomy of risks factors and exemplar risks proposed in Refs. [8,9]. In addition, this paper focused on the best application of these management strategies for a well-managed and healthier implementation of the gamification system in a teamwork environment.

As a method, we conducted several qualitative studies including expert interviews, an observational study and focus groups supported by card sorting technique to establish a taxonomy of risks, their factors and management strategies. By analysing the collected data, we identified different modalities of application of the management strategies and various types of stakeholders to be involved in the decision-making session to decide the applicability of the management strategies for the identified or predicted gamification risks. Finally, we proposed a checklist to facilitate risk identification process. This was meant to answer the research main questions about (i) how to identify 
gamification related risks, and (ii) how to manage them for best application of the system in the teamwork context.

Given the ethical considerations associated with gamification and its human-intense nature, this research recommends using participatory decision style as an approach for future methods that focus on the analysis of gamification risks and their resolution. Hence, employing techniques such as role-playing, rehearsal, simulation and scenarios may help to exploring and uncovering ethical concerns through groups discussions and prototyping exercises. We also recommend studying how to integrate the risk identification processes, which should take an iterative participatory style with the systems' development life cycle activities and other models including requirements models.

The complexity in analysing the dependency amongst workers and assigned tasks in addition to their trajectories with personality traits, goals, expectations and gamification risks sources suggest the need for devising a systematic approach for analysing such complex dependency environments. This requires providing bespoke modelling languages or domain-specific languages to cater for the peculiarities of such concepts, relationships and their semantics and ensure that they are expressive enough to accommodate such complexity. Automated reasoning and recommender systems to help groups and system analysts predict risks will be also needed especially for large scale systems and their models. We intend to utilise the results presented in this paper and develop a method for gamification risk management that includes risks detection and assessment alongside with their mitigation strategies from the early stages of the system analysis.

Author Contributions: Conceptualisation, A.A. (Abdullah Algashami) and R.A.; Formal analysis, A.A. (Abdullah Algashami); Investigation, A.A. (Abdullah Algashami), L.V., A.A. (Amen Alrobai) and R.A.; Methodology, A.A. (Abdullah Algashami), L.V. and R.A.; Project administration, R.A.; Supervision, L.V., K.P. and R.A.; Validation, A.A. (Abdullah Algashami) and Amen Alrobai; Writing—original draft, A.A. (Abdullah Algashami); Writing-review and editing, L.V., A.A. (Amen Alrobai) and R.A.

Funding: This research received no external funding.

Conflicts of Interest: The authors declare no conflict of interest.

\section{References}

1. King, D.; Greaves, F.; Exeter, C.; Darzi, A. “Gamification”: Influencing health behaviours with games. JRSM 2013, 106, 76-78. [CrossRef] [PubMed]

2. Herzig, P.; Ameling, M.; Schill, A. A Generic Platform for Enterprise Gamification. In Proceedings of the 2012 Joint Working IEEE/IFIP Conference on Software Architecture and European Conference on Software Architecture, Helsinki, Finland, 20-24 August 2012; pp. 219-223.

3. Simões, J.; Redondo, R.D.; Vilas, A.F. A social gamification framework for a K-6 learning platform. Comput. Hum. Behav. 2013, 29, 345-353. [CrossRef]

4. Lacroix, J.; Saini, P.; Goris, A. Understanding user cognitions to guide the tailoring of persuasive technology-based physical activity interventions. In Proceedings of the 4 th International Conference on Persuasive Technology, Claremont, CA, USA, 26-29 April 2009.

5. Shahri, A.; Hosseini, M.; Phalp, K.; Taylor, J.; Ali, R. Towards a Code of Ethics for Gamification at Enterprise. PoEM 2014, 197, 235-245.

6. Forsyth, D. An Introduction to Group Dynamics; Brooks/Cole Publishing Company: Pacific Grove, CA, USA, 1992.

7. Shahri, A.; Hosseini, M.; Phalp, K.; Taylor, J.; Ali, R. How to Engineer Gamification: The Consensus, the Best Practice and the Grey Areas. Available online: http:/ / eprints.bournemouth.ac.uk/28253/ (accessed on 27 August 2018).

8. Algashami, A.; Cham, S.; Vuillier, L.; Stefanidis, A.; Phalp, K.; Ali, R. Conceptualising Gamification Risks to Teamwork within Enterprise. In The Practice of Enterprise Modeling; Springer: Cham, Switzerland, 2018. [CrossRef]

9. Algashami, A.; Shahri, A.; McAlaney, J.; Taylor, J.; Phalp, K.; Ali, R. Strategies and Design Principles to Minimize Negative Side-Effects of Digital Motivation on Teamwork. PERSUASIVE 2017, 10171, 267-278. [CrossRef] 
10. Nicholson, S. A user-centered theoretical framework for meaningful gamification. In Proceedings of the Games+ Learning+ Society 8.0, Madison, WI, USA, 13-15 June 2012.

11. Huotari, K.; Hamari, J. Defining gamification-A service marketing perspective. In Proceedings of the 16 th Inernational Academic MindTrek Conference, Tampere, Finland, 3-5 October 2012.

12. Deterding, S. Gamification - designing for motivation. Interactions 2012, 19, 14. [CrossRef]

13. Marczewski, A. Gamification Design vs. Game Design. Available online: https://www.gamified.uk/2014/ 03/25/gamification-design-vs-game-design/ (accessed on 27 August 2018).

14. Kumar, J. Gamification at Work-Designing Engaging Business Software. HCI 2013, 8013 LNCS, 528-537.

15. Apter, M.J.; Kerr, J.H. Adult Play: A reversal theory approach; Garland Science: New York, NY, USA, 1991.

16. Thiebes, S.; Lins, S.; Basten, D. Gamifying Information Systems-A synthesis of Gamification mechanics and Dynamics. In Proceedings of the European Conference on Information Systems (ECIS), Tel Aviv, Israel, 9-11 June 2014.

17. Challco, G.C.; Moreira, D.A.; Mizoguchi, R.; Isotani, S. An ontology engineering approach to gamify collaborative learning scenarios. In Collaboration and Technology; Springer International Publishing: Cham, Switzerland, 2014.

18. Bouzidi, R.; De Nicola, A.; Nader, F.; Chalal, R. OntoGamif Ontology: A Modular Ontology for the Gamification Domain. Mendeley 2018. [CrossRef]

19. Barata, J.; da Cunha, P.R.; Abrantes, L. Dealing with Risks and Workarounds-A Guiding Framework. PoEM 2015, 235, 141-155.

20. Alter, S.; Sherer, S.A. A General, But Readily Adaptable Model of Information System Risk. CAIS 2004, 14, 35. [CrossRef]

21. Zur Muehlen, M.; Rosemann, M. Integrating risks in business process models. In Proceedings of the 16th Australasian Conference on Information Systems (ACIS 2005), Sydney, Australia, 30 November-2 December 2005.

22. Suriadi, S.; Weiß, B.; Winkelmann, A.; ter Hofstede, A.H.M.; Adams, M.; Conforti, R.; Fidge, C.; La Rosa, M.; Ouyang, C.; Pika, A.; et al. Current research in risk-aware business process management-overview, comparison, and gap analysis. CAIS 2014, 34, 933-984. [CrossRef]

23. Annamalah, S.; Raman, M.; Marthandan, G.; Logeswaran, A. Implementation of Enterprise Risk Management (ERM) Framework in Enhancing Business Performances in Oil and Gas Sector. Economies 2018, 6, 4. [CrossRef]

24. Karachaliou, T.; Protonotarios, V.; Kaliampakos, D.; Menegaki, M. Using Risk Assessment and Management Approaches to Develop Cost-Effective and Sustainable Mine Waste Management Strategies. Recycling 2016, 1, 328. [CrossRef]

25. Inanoglu, H.; Jacobs, M., Jr. Models for Risk Aggregation and Sensitivity Analysis: An Application to Bank Economic Capital. JRFM 2009, 2, 118-189. [CrossRef]

26. Vilpola, I.; Ojala, M.; Kouri, I. Risks and Risk Management in ERP Project-Cases in SME Context. BIS 2006, 179-186.

27. Kaassis, B.; Badri, A. Development of a Preliminary Model for Evaluating Occupational Health and Safety Risk Management Maturity in Small and Medium-Sized Enterprises. Safety 2018, 4, 5. [CrossRef]

28. Zoet, M.; Welke, R.; Versendaal, J.; Ravesteyn, P. Aligning Risk Management and Compliance Considerations with Business Process Development. E-Commerce Web Technol. 2009, 5692, 157-168.

29. Stirna, J.; Zdravkovic, J.; Grabis, J.; Sandkuhl, K. Development of Capability Driven Development Methodology—Experiences and Recommendations. PoEM 2017, 305, 251-266.

30. Morschheuser, B.; Hassan, L.; Werder, K.; Hamari, J. How to design gamification? A method for engineering gamified software. Inf. Softw. Technol. 2018. [CrossRef]

31. Saunders, M.; Lewis, P.; Thornhill, A. Research Methods for Business Students; Pearson Education: London, UK, 2009.

32. Deterding, S.; Dixon, D.; Khaled, R.; Nacke, L. From game design elements to gamefulness—defining "gamification". In Proceedings of the 15th International Academic MindTrek Conference: Envisioning Future Media Environments, Tampere, Finland, 28-30 September 2011.

33. von Ahn, L. Games with a Purpose. IEEE Comput. 2006, 39, 92-94. [CrossRef]

34. Fogg, B.J. Creating persuasive technologies-An eight-step design process. PERSUASIVE 2009, 350, 1.

35. Boehm, B.W. Software risk management: principles and practices. IEEE Softw. 1991, 8, 32-41. [CrossRef] 
36. Friedman, B.; Kahn, P.H.; Borning, A.; Huldtgren, A. Value Sensitive Design and Information Systems. In Early Engagement and New Technologies: Opening up the Laboratory; Springer: Dordrecht, The Netherlands, 2013; Volume 16, pp. 55-95.

37. Dion, K.L. Group cohesion: From "field of forces" to multidimensional construct. Group Dyn. 2000, 4, 7-26. [CrossRef]

38. Shahri, A.; Hosseini, M.; Phalp, K.; Taylor, J.; Ali, R. Exploring and Conceptualising Software-Based Motivation Within Enterprise. PoEM 2016, 267, 241-256.

39. Braun, V.; Clarke, V. Using thematic analysis in psychology. Qual. Res. Psychol. 2006, 3, 77-101. [CrossRef]

40. Viswesvaran, C.; Ones, D.S. Perspectives on Models of Job Performance. Int. J. Sel. Assess. 2000, 8, $216-226$. [CrossRef]

41. Ball, K.S.; Margulis, S.T. Electronic monitoring and surveillance in call centres: A framework for investigation. New Technol. Work Employ. 2011, 26, 113-126. [CrossRef]

42. Liu, Y.; Alexandrova, T.; Nakajima, T. Gamifying Intelligent Environments; ACM Press: New York, NY, USA, 2011.

43. Raftopoulos, M. Towards gamification transparency: A conceptual framework for the development of responsible gamified enterprise systems. J. Gaming Virtual Worlds 2014, 6, 159-178. [CrossRef]

44. Greenberg, B.S.; Sherry, J.; Lachlan, K.; Lucas, K.; Holmstrom, A. Orientations to Video Games Among Gender and Age Groups. Simul. Gaming 2008, 41, 238-259. [CrossRef]

45. Griffiths, M.D.; Davies, M.N.O.; Chappell, D. Breaking the stereotype: The case of online gaming. Cyberpsychol. Behav. 2003, 6, 81-91. [CrossRef]

46. Williams, D.; Consalvo, M.; Caplan, S.; Yee, N. Looking for Gender: Gender Roles and Behaviors Among Online Gamers. J. Commun. 2009, 59, 700-725. [CrossRef]

47. Koivisto, J.; Hamari, J. Demographic differences in perceived benefits from gamification. Comput. Hum. Behav. 2014, 35, 179-188. [CrossRef]

48. Ryan, R.M.; Deci, E.L. Self-determination theory and the facilitation of intrinsic motivation, social development, and well-being. Am. Psychol. 2000, 55, 68-78. [CrossRef] [PubMed]

49. Locke, E.A.; Latham, G.P. Building a practically useful theory of goal setting and task motivation: A 35-year odyssey. Am. Psychol. 2002, 57, 705-717. [CrossRef]

50. Locke, E.A.; Latham, G.P.; Erez, M. The Determinants of Goal Commitment. Acad. Manag. Rev. 1988, 13, 23-39. [CrossRef]

51. Erez, M.; Zidon, I. Effect of goal acceptance on the relationship of goal difficulty to performance. J. Appl. Psychol. 1984, 69, 69-78. [CrossRef]

52. Locke, E.A. Relation of goal level to performance with a short work period and multiple goal levels. J. Appl. Psychol. 1982, 67, 512-514. [CrossRef]

53. Kim, T.W.; Werbach, K. More than just a game: ethical issues in gamification. Ethics Inf. Technol. 2016, 18, 157-173. [CrossRef]

54. Penner, L.A.; Dovidio, J.F.; Piliavin, J.A.; Schroeder, D.A. Prosocial Behavior: Multilevel Perspectives. Ann. Rev. Psychol. 2005, 56, 365-392. [CrossRef]

55. McGillicuddy, N.B.; Pruitt, D.G.; Syna, H. Perceptions of Firmness and Strength in Negotiation. Person. Soc. Psychol. Bull. 1984, 10, 402-409. [CrossRef]

56. Forgas, J.P. On feeling good and getting your way: Mood effects on negotiator cognition and bargaining strategies. J. Person. Soc. Psychol. 1998, 74, 565-577. [CrossRef]

57. Berdichevsky, D.; Neuenschwander, E. Toward an ethics of persuasive technology. Commun. ACM 1999, 42, 51-58. [CrossRef]

58. Kensing, F.; Blomberg, J. Participatory Design: Issues and Concerns. Comput. Supported Coop. Work (CSCW) 1998, 7, 167-185. [CrossRef]

59. De Colle, S. A stakeholder management model for ethical decision making. Int. J. Manag. Decis. Mak. 2005, 6, 299. [CrossRef]

60. Ethics, C.C.F.B. Principles of Stakeholder Management; University of Toronto: Toronto, ON, Canada, 1999.

61. Herzig, P.; Ameling, M.; Wolf, B.; Schill, A. Implementing Gamification: Requirements and Gamification Platforms. In Gamification in Education and Business; Springer: Cham, Switzerland, 2015; pp. 431-450.

62. Marczewski, A.C. Even Ninja Monkeys Like to Play: Gamification, Game Thinking \& Motivational Design.; Blurb: San Francisco, CA, USA, 2015. 
63. Wallmüller, E. Risk Management for IT and Software Projects. In Business Continuity; Springer: Berlin/Heidelberg, Germany, 2002; pp. 165-178.

64. Fogg, B.J. Persuasive Technology: Using Computers to Change What We Think and Do (Interactive Technologies); Morgan Kaufmann: Burlington, MA, USA, 2002.

65. Versteeg, M.J.J.M. Ethics \& Gamification Design: A Moral Framework for Taking Responsibility. Master's Thesis, Universiteit Utrecht, Utrecht, The Netherlands, 2013.

66. Okoli, C.; Pawlowski, S.D. The Delphi method as a research tool: An example, design considerations and applications. Inf. Manag. 2004, 42, 15-29. [CrossRef] 